\title{
O DESENVOLVIMENTO MORAL SOB A TEORIA PIAGETIANA: CONCEPÇÕES DE FURTO NO ENSINO FUNDAMENTAL
}

Josiane Paula Rodrigues Azevedo

Universidade Estadual Paulista- UNESP, UNESP/IBILCE, Programa de Pós-Graduação em Ensino e Processos Formativos, Departamento de Educação, São José do Rio Preto, SP. E-mail: josipr.azevedo@gmail.com

\section{RESUMO}

O presente estudo investigou o furto em ambiente escolar fundamentado no trabalho pioneiro de Jean Piaget, "O julgamento moral da criança", para refletir a moralidade infantil em diferentes classes sociais. 36 crianças de escolas públicas e particulares participaram de entrevistas clínicas e analisamos suas respostas e justificativas para as histórias-estímulo apresentadas. Assim, verificamos que as crianças de ensino fundamental demonstram consciência às regras e a capacidade de julgar as atitudes dos personagens. Uma grande parcela dela manifestou justificativas estereotipadas, principalmente as de baixo nível sócio-econômico. Desse modo, percebe-se que o julgamento da criança nessa faixa etária se estabelece nas relações com os adultos, principalmente os pais ou a família no geral, que transmitem regras morais prontas, sem que elas possam elaborá-las de acordo com suas necessidades e interesses. Professores também têm um papel de destaque na imposição das regras, sobretudo na atual situação de crise familiar. PALAVRAS-CHAVE: Desenvolvimento moral; Julgamento sócio moral; Furto.

\section{THE MORAL DEVELOPMENT ACCORDING TO PIAGET'S THEORY: THE CONCEPT OF THEFT IN THE ELEMENTARY SCHOOL}

\begin{abstract}
The present study performed investigations about theft in the school environment based on the pioneering work of Jean Piaget, "The moral judgment of the child", to discuss child's co in different social classes. 36 children from public and private schools participated in clinical interviews and analyzed their answers and justifications for the presented stimulus stories were analyzed. Thus, we found that elementary school's children demonstrate awareness of the rules and the ability to judge the characters' attitudes. A large part of it manifested stereotyped justifications, especially those of low socioeconomic level. Thus, the child's judgment in this age group seems to be established in relationships with adults, especially the parents or other family members, who transmit ready-made moral rules, without them being able to elaborate them according to their needs and interests. Teachers also have a prominent role in enforcing the rules, especially in the current situation of family crisis.
\end{abstract}

KEYWORDS: Moral development; Sociomoral judgment; Thef 


\section{INTRODUÇÃO}

Desde o nascimento, a criança está em constante desenvolvimento e, ao interagir com seu meio, passa a conhecer os atos que são aceitos ou não pelo grupo social no qual está inserida. Esta apropriação de conhecimentos se dá pelas relações estabelecidas no ambiente familiar, escolar e na sociedade como um todo e permitem que a criança forme, assim, a sua consciência ou juízo moral (MENIN, 2012). Não se trata de um acontecimento imediato, mas de um processo que vai ocorrendo durante toda a infância.

Piaget (1994) percebeu que, em um ambiente que privilegia a construção da autonomia, o respeito unilateral da criança pelo adulto vai sendo substituído pelo respeito mútuo, numa relação entre iguais na qual a autoridade vai perdendo a sua força. Assim, a partir de seis ou sete anos, a criança começa a construir sua moral autônoma. Na fase da autonomia, a criança já é capaz de considerar a intenção dos atos e a cooperação. Portanto, para desenvolver a autonomia é necessário promover a socialização, o convívio com colegas da mesma idade.

Oliveira (2001) analisa a ética na escola e a formação do caráter do aluno e aborda o papel cumprido pela escola na formação moral do cidadão. $O$ autor conclui que as discussões sobre ética/moral na escola são um assunto inacabado e complexo e que a escola não é o principal agente formador do caráter. Para ele, as contribuições da escola são parte de um processo no qual intervêm diversos atores: família, amigos, grupo religioso, etc. No cotidiano escolar, os valores se traduzem no regulamento escolar e nas finalidades do ensino e aprendizagem.

Atualmente, muitos professores sentem-se impotentes e inseguros ao se depararem com problemas cada vez mais frequentes de indisciplina, de violência ou de conflitos (VINHA, 2003). Desse modo, se torna cada vez mais importante a compreensão da concepção da criança diante de certas situações sócio-morais, de como que a criança organiza o seu pensamento, o que ela acha certo ou errado. Essas são questões que o educador deve se preocupar em conhecer, pois, segundo os Parâmetros Curriculares Nacionais, os professores devem trabalhar com temas éticos na sala de aula (BRASIL, 1997). Desse modo, essa pesquisa buscou investigar a concepção de furto entre crianças, de modo que possa auxiliar os professores a conhecer o desenvolvimento sóciomoral das crianças diante dessas condutas.

\section{MÉTODO}

As crianças participantes da pesquisa são alunos do terceiro ano do ensino fundamental, 18 delas atendidas por uma escola particular (Escola 1) de um bairro de classe media alta da cidade de São José do Rio Preto (SP) e 18 de uma escola pública (Escola 2) de um bairro de classe baixa da mesma cidade.

O convite aos alunos foi de forma aberta e, aos participantes, foi entregue um termo de consentimento em que os pais e/ou responsáveis legais autorizam a participação de sua(s) criança(s) na pesquisa. Sendo assim, participaram do estudo apenas as crianças que tiverem permissão dos responsáveis, conforme termo de consentimento devidamente assinado. Ao todo, foram entrevistadas 36 crianças de ambos os sexos, 24 masculino e 12 feminino, com idade aproximada de 8 anos. A pesquisa o foi aprovada pelo Comitê de Ética em Pesquisa de acordo com o número CAAE da Plataforma Brasil (0021.0.229.000-10) sob o parecer de № 007/10.

O instrumento utilizado para a coleta de dados (entrevista clínica) foi composto de dois questionários. O primeiro referente às três histórias-estímulo destacando a ocorrência de furto em ambiente escolar e o segundo para averiguar se os alunos conseguiram fazer relação do tema proposto nas três histórias. As histórias-estímulo foram elaboradas de maneira que representassem condutas próximas às situações vividas ou observadas pelas crianças no ambiente escolar.

A primeira história, intitulada "Achado não é roubado", foi construída para analisar a concepção de furto das crianças em situações em que o objeto interceptado não tem um dono 
implícito, conhecido. A narrativa apresentada foi a seguinte: "Um menino estava andando pela sala de aula e encontra, no chão, uma caneta. Sem perguntar se a caneta é de algum amigo, ele pega a caneta e guarda em sua mochila".

A segunda história, denominada "Pedir emprestado sem devolver", buscou analisar a concepção da criança no ato de pedir emprestado um objeto e não devolver ao dono após usar e foi estruturada deste modo: "Durante a aula, uma menina pede emprestado um lápis para o seu amigo de classe. Ela usa o lápis em seu desenho, guarda em seu estojo, e não devolve para o seu amigo que havia emprestado o lápis".

A terceira e ultima história apresentada, "Se não tenho, posso pegar do meu colega que tem muito", considerou a questão de justiça. Será que a criança acha justo ela não ter um objeto enquanto seu colega de classe tem muito? Este fato justifica o ato de pegar do colega? Para avaliar estas questões apresentamos a história: "Durante a aula, uma menina queria muito uma caneta colorida, mas ela não tinha essa caneta. Então, ela viu que seu amigo tinha muitas canetas coloridas e resolveu pegar uma quando ele não estivesse perto. Como ele tinha muitas canetas, ela pegou uma e guardou dentro da mochila dela".

As histórias-estímulo foram apresentadas às crianças que, logo em seguida, responderam quatro questões principais: 1a) "O que o personagem da história fez?" refere à justificativa da ação do personagem da história numa dada situação; 2ạ) "É certo ou errado o que ela fez?" avalia o julgamento moral da criança; $3^{3}$ ) "Porque é certo ou errado?" analisa sua concepção sobre a gravidade da conduta; 4a) "O que ela deveria fazer?" refere à atitude sugerida pela criança nesta mesma situação.

Os resultados foram analisados utilizando-se o modelo social cognitivo dos domínios, que avalia as justificativas dos participantes para os atos pesquisados e categoriza as respostas para o julgamento das ações. Estas análises objetivaram o entendimento da concepção das crianças diante uma situação de roubo, visando conhecer como elas categorizam esta conduta, seu julgamento sócio-moral. Todas as justificativas usadas pelas crianças foram classificadas e formaram um conjunto de oito categorias: "Regra simples", "Estereotipadas", "Consciência da Regra", "Consciência social", "Indiferenciadas", "Ações Punitivas", "Subordinação a terceiros" e "Outras". Para cada uma destas categorias, foram calculadas as frequências observadas e a proporção de cada uma das categorias de justificação por escola.

\section{RESULTADOS}

Após a aplicação dos questionários, analisamos o discurso das crianças em relação a situações de furto que envolvem conceitos de moralidade. As respostas das crianças são apresentadas por questão e escolas.

\section{QUESTÃO №1}

Na primeira questão aplicada perguntou-se às crianças o que o personagem da história fez. As justificativas dadas pelas crianças nesta questão se distribuíram em três diferentes categorias $A$ primeira delas é formada pelas crianças que classificam o ato apresentado como simplesmente "pegar". Esta categoria é classificada como "regra simples" porque demonstra que a criança é capaz de compreender uma regra social de reciprocidade, iniciando a construção de uma moral autônoma. As crianças incluídas na segunda categoria usam justificativas "estereotipadas" e consideram a ação da personagem um "roubo". Esta categoria compreende padrões de resposta que as crianças repetem; algo que aprenderam um estereótipo. A terceira categoria, de justificativas "indiferenciadas", representa aqueles alunos que apenas consideram errada a atitude do personagem, sem classificá-la. Nessa categoria, temos maior incidência de alunos da escola pública, em ambas as histórias. As crianças não encontraram dificuldade em julgar o outro. Isso 
justifica o fato de apenas $16 \%$ dos alunos apenas considerar errado e os demais alunos representarem seu julgamento.

\section{QUESTÃO №2}

A partir da resposta anterior, os alunos deveriam definir se a atitude do personagem da história é correta ou errada. Na questão 2 da primeira história, obtivemos $94,4 \%$ de concordância como evento social errado e 5,6\% que disseram que é certo. As crianças de defenderam que era certo justificaram que o personagem "achou no chão e pegou o lápis para entregar para o dono". Nesse sentido, podemos supor que as crianças definiram o pensamento do personagem. Na questão 2 da segunda e terceira história, temos $100 \%$ das crianças respondendo que o personagem da história fez uma coisa errada. Quando relacionamos estas respostas com as da questão anterior, percebemos que os alunos consideram errado tanto o "pegar" como o "roubar", ou seja, os alunos reconhecem que tais atitudes são erradas diante da regra estabelecida pela sociedade, que não se deve tomar para si algo que não lhe pertence.

\section{QUESTÃO №3}

$\mathrm{Na}$ questão 3 procurou-se verificar a justificativa em relação à resposta anterior. Ao fazermos nossa análise, consideramos que este raciocínio é mais complexo, pois, as crianças apresentam um julgamento em termos de intenção e consequência, raciocinando em termos do porquê do ato. A grande maioria das respostas foi classificada na categoria "Consciência da Regra". São as respostas em que se encontra referência a conhecimento da regra já estabelecida em relação à atitude do personagem. Como nesta questão destacamos apenas uma categoria, abordaremos cada história individualmente. Na primeira história, 38,9\% dos alunos da escola 1, particular, julgaram o ato errado porque o personagem "pegou algo que não era dele". Na escola pública, as respostas se dividiram em cinco justificativas para considerar a ação como errada: $27,8 \%$ "porque ele roubou"; $22,2 \%$ "porque não perguntou quem era o dono"; $16,7 \%$ "porque não devolveu" e apenas $11,1 \%$, o oposto da particular, explicaram "porque pegou o que não era dele". Nesta história, por expressar um furto implícito, as crianças apresentam diversas justificativas.

$\mathrm{Na}$ história 2 temos um dado em comum entre as escolas, em ambas mais da metade dos alunos justificaram com "porque não devolveu". Nota-se a importância que as crianças conferem para o ato de devolver o objeto que foi emprestado. Os resultados mostram uma resposta mais elaborada em que as crianças demonstram consciência às regras. Nesse sentido, a criança começa a formar uma regra social.

$\mathrm{Na}$ terceira história observamos uma grande variação das respostas entre as escolas. $\mathrm{Na}$ justificativa, "porque não pediu emprestado", foi a resposta mais comum tanto na escola 1, com $38.9 \%$, quanto na escola 2 , com $44,4 \%$ das respostas. Nota-se também uma divergência entre as respostas. Enquanto 33,3\% dos alunos da escola 1, responderam, "porque pegou algo que não pertencia", na escola 2 nenhum aluno fez essa justificativa.

Observamos na categoria de "consciência às regras", que as crianças, no momento de justificarem porque é errada a ação do personagem, nas três histórias, demonstram ter conhecimento e respeito pelas regras estabelecidas. Essas regras são instruídas na criança tanto pelo convívio familiar como no social e fazem referência ao modo como a criança deve se comportar nas situações sociais, fazendo parte do domínio moral.

\section{QUESTÃO №4}

Na quarta questão pergunta-se às crianças o que o personagem das histórias deveria fazer? Na análise comparativa dos dados, encontramos entre a turma da escola particular e a da escola pública um mesmo padrão de respostas, isto é, a maior parte dos alunos respondeu que este o personagem "deveria devolver" o objeto que não lhe pertence. Esta resposta se adequa a 
categoria de "Consciência social". São respostas que se referem à atitude que deveria ser tomada pelo personagem. Nesta categoria, a criança reconhece o ato como errado e estabelece um procedimento correto, como por exemplo, as demais respostas: "perguntar quem é o dono", "entregar para a professora" e "não roubar".

Na segunda história, os resultados foram semelhantes em ambas às escolas, sendo que $100,0 \%$ dos alunos na escola particular e $88,9 \%$ dos alunos da escola pública responderam que o personagem deveria devolver o objeto. Essa semelhança acontece também na terceira história. Encontramos, praticamente, unanimidade entre as crianças de ambas as escolas: que se deve "pedir emprestado" antes de pegar do amigo. Nota-se que, na categoria "Consciência social", as crianças reproduzem a uma regra instituída, construída e interiorizada pelas crianças como ações que devem ser adotadas. Isso reflete no padrão de sugestões apresentadas pelas crianças quando se pergunta o que se deveria fazer.

\section{DISCUSSÃO}

A intenção desta pesquisa foi analisar a concepção de furto entre dos alunos do ensino fundamental, procurando contrastar nossas observações com os estudos de Jean Piaget sobre moralidade. O método escolhido para o estudo foi o uso de histórias-estímulo, seguidas da aplicação de questionários para avaliação dos critérios de julgamento e justificativas dadas pelas crianças. Desta forma, pudemos comparar os resultados aos estudos sobre desenvolvimento moral realizado por Piaget.

Com base no referencial teórico analisado, concluímos que a formação da concepção de roubo pela criança se estabelece nas relações com os adultos, principalmente os pais ou a família no geral, que transmitem regras morais prontas, sem que elas possam elaborá-las de acordo com suas necessidades e interesses. Professores também têm um papel de destaque na imposição das regras, sobretudo na atual situação de crise familiar.

Dentre os fatores que influenciam a formação do desenvolvimento moral, destacamos o nível socioeconômico. Crianças pertencentes ao nível socioeconômico mais elevado demonstram um senso crítico mais desenvolvido. Estas crianças explicaram as situações apresentadas na pesquisa utilizando a categoria de "Regra simples", evidenciando capacidade de elaborar uma justificativa correspondente a regra. Elas estão inseridas em um ambiente que fornece mais recursos e uma formação integral, que possibilita ter acesso a valores éticos, que são ensinados na própria família e pelas escolas.

As crianças de nível socioeconômico baixo utilizam-se, principalmente, de respostas estereotipadas, um discurso moral padronizado, inconsciente, como se tivessem "decorado" tal fala. O contexto social vivenciado por essas crianças é, muitas vezes, marcado por situações problemáticas e desvios de conduta. Esses fatores, quando não esclarecidos, tornam-se um problema social, pois a criança passa a não ter o entendimento do porque o furto é errado.

Entretanto, por mais que o fator socioeconômico seja importante, é difícil avaliar o grau de sua influencia na formação moral. Cada indivíduo possui suas particularidades em sua personalidade, ao ponto que, até mesmo irmãos, que recebem a mesma educação e compartilham do mesmo ambiente socioeconômico, podem demonstrar condutas morais muito distintas (MARTINS, 1997). No entanto, o nível socioeconômico possibilita a criança a ter acesso a convívio social e ao conhecimento e da prática da ética favorecendo a construção moral.

Regras e valores são transmitidos em inúmeras situações do cotidiano escolar: nas regras instituídas pelas escolas, combinados estabelecidos com os alunos em sala de aula, nas relações de comportamento dos alunos, pela maneira como o conteúdo é trabalhado e pela forma que os professores disciplinam e organizam o espaço físico (ARAÚJO, 1996). Segundo os Parâmetros Curriculares, a própria função da escola - socialização do saber - levanta questões éticas e relativas a valores humanos que permeiam também os conteúdos curriculares. Desse modo, as 
relações sociais internas são pautadas em valores morais, como a relação professor com aluno, escola com a comunidade e como articular conhecimentos com a necessidade da realidade do aluno.

A educação moral e a presença pedagógica junto ao educando que tem como objetivo o despertar de suas competências morais. Nesse sentido, é importante que o professor tenha conhecimento da teoria. Ao tomar conhecimento de como a criança se desenvolve e quais são as características do estágio do desenvolvimento em que se encontra o professor passa a ter uma maneira diferente de compreender as ações e reações dos alunos, sem realizar julgamentos (VINHA, 2003). Sendo assim, ao estudar o papel da ética na formação do individuo, o professor atuará no processo educativo de forma consciente contribuído para o amplo desenvolvimento dos alunos. A partir desses, apontamentos a instituição pode contribuir muito para o desenvolvimento da moralidade.

\section{CONCLUSÃO}

Concluímos que o desenvolvimento moral está associado ao desenvolvimento dos sentimentos, crenças, valores e princípios socialmente estabelecidos. Este é influenciado pelos juízos morais, pela capacidade de inibir condutas antissociais e pela habilidade de realizar condutas valorizadas como morais. Todo esse processo de construção da moralidade está relacionado a uma etapa evolutiva que passa da heterônoma para a autonomia, a uma cultura e a um processo de socialização instruído pelo convívio social. Portanto, a moralidade está constituída pelo aspecto social.

\section{REFERÊNCIAS}

ARAÚJO, U. F. Moralidade e indisciplina: uma leitura possível a partir do referencial piagetiano. In. AQUINO, J. G. (Org.) Indisciplina na escola: alternativas teóricas e práticas. São Paulo, 1996.

BRASIL. Secretaria de Educação Fundamental. Parâmetros Curriculares Nacionais: apresentação dos temas transversais, ética. Brasília: MEC/SEF,1997. (volume 8)

MARTINS, R. A. Concepção de roubo em pré-escolares. Educ. Soc., Campinas, v. 18, n. 59, ago. 1997.

MENIN, M. S. S. Valores na escola. Educação e Pesquisa. São Paulo, v. 28, n. 1, p. 91-100, jan/jul. 2002

OLIVEIRA, R. J. de. Ética na Escola: (re)acendendo uma polêmica. Educ. Soc. v.22 n.76. Campinas. Out/ 2001.

PIAGET, J. O julgamento moral na criança. São Paulo: Summus, 1994.

VINHA T. P. O educador e a moralidade infantil: uma visão construtivista. 2. Ed. Campinas: Mercado das Letras/FAPESP, 2003. 